\title{
MASS TRANSFER ALONG AN IGE SURFACE OBSERVED BY A GROOVE RELAXATION TECHNIQUE
}

\author{
By K. Itagaki and T. M. Tobin \\ (U.S. Army Cold Regions Research and Engineering Laboratory, Hanover, New Hampshire \\ o3755, U.S.A.)
}

\begin{abstract}
The mass transfer on an ice surface was measured using a groove decay technique on (ooor) plane and $\langle\mathrm{IO} \overline{\mathrm{I} O}\rangle$ direction at $-10^{\circ} \mathrm{C}$. The evaporation-condensation and viscous flow terms in Mullins' theory were deduced from the change of decay constant as a function of groove wavelength between 16 and $80 \mu \mathrm{m}$. A viscous flow term contributes the most to groove decay while an evaporation-condensation term contributes up to $31.5 \%$ of the mass transfer for the shortest wavelength measured and other terms were found to be negligible. Large discrepancies between the decay constants obtained from the measurements and constants calculated from theory indicate that other mechanisms not considered in Mullins' theory may be responsible for the groove decay.
\end{abstract}

Résumé. Transferts de masse le long d'une surface de glace par une technique de relaxation des sillons. Les transferts de masse sur une surface de glace ont été mesurés en utilisant une technique de la décroissance des sillons le long du plan $(\mathrm{OOOI})$ et de la direction $\langle\mathrm{IO} \overline{\mathrm{I} O}\rangle$ à $-10^{\circ} \mathrm{C}$. Les termes d'évaporation-condensation et d'écoulement visqueux dans la théorie de Mullins ont été déduits des variations de la constante de décroissance en fonction de la longeur d'onde des sillons entre i 6 et $80 \mu \mathrm{m}$. C'est l'écoulement visqueux qui contribue le plus à la decroissance des sillons, tandis que l'évaporation-condensation n'y participe que pour $31,5 \%$ des transferts de masse mesurés pour la plus courte longeur d'onde, et que les autres termes apparaissent négligeables. D'importantes descordances entre les constantes de décroissance obtenues à partir des mesures et les constantes calculées par la théorie prouvent que d'autres mécanismes, non pris en compte dans la théorie de Mullins, peuvent être responsables de la décroissance des sillons.

Zusammenfassung. Massentransport entlang einer Eisoberfläche-beobachtet aus dem Verfall von Rillen. Der Massentransport auf einer Eisoberfläche wurde aus dem Verfall der Rillen in der (OOOI)-Fläche und $\langle\mathbf{I O} \overline{\mathrm{I} O}\rangle$ Richtung bei $-10^{\circ} \mathrm{C}$ gemessen. Die Ausdrücke für Verdunstung-Kondensation und viskoses Fliessens in Mullins' Theorie wurden aus den Änderungen der Verfallskonstanten als Funktion der Wellenlänge der Rillen zwischen 16 und $80 \mu \mathrm{m}$ hergeleitet. Viskoses Fliessen verursacht den Hauptanteil der Rillenauflösung, während die Verdunstung und Kondensation bis zu $31,5 \%$ des Massentransports für die kürzeste der gemessenen Wellenlängen ausmacht. Weitere Einflüsse stellten sich als vernachlässigbar heraus. Grosse Abweichungen zwischen den Verfallskonstanten, die sich aus den Beobachtungen ergaben, und den aus der Theorie errechneten deuten darauf hin, dass noch andere Mechanismen, die in Mullins' Theorie nicht berücksichtigt sind, den Rillen-Verfall mitverursachen.

\section{INTRODUCTION}

An attempt to study the surface structure of ice was made using a mass-transfer measurement. The method most extensively adopted to measure surface mass transfer is the observation of the relaxation of surface grooves. According to Mullins (1959), a surface which initially has a sinusoidal profile in the $z-x$ plane of $z=z_{0} \sin \omega x$ will decay with time $t$ as

$$
z(x, t)=z_{0} \sin \omega x \exp \left[-\left(B \omega^{4}+C \omega^{3}+A^{\prime} \omega^{3}+A \omega^{2}+F \omega\right) t\right]
$$

where $\omega=2 \pi / \lambda$ is the frequency of the grooves and $B, C, A^{\prime}, A$ and $F$ are constants depending on the mass-transfer mechanisms. The values of these constants at a particular wavelength and temperature indicate the relative contribution of each mechanism to the total relaxation.

If $\beta$, the mean free path of the molecules from the solid in the non-reactive atmosphere, is much greater than the wavelength, the evaporation-condensation mechanism contributes to the surface relaxation as $A \omega^{2}$ where

$$
A=\frac{p_{0} \gamma_{\mathrm{s}} \Omega^{2}}{(2 \pi M)^{\frac{1}{2}}(k T)^{\frac{3}{2}}}
$$

here $p_{0}$ is the equilibrium vapor pressure over a flat surface, $\gamma_{\mathrm{s}}$ is the surface free energy of the solid, $\Omega$ is the molecular volume, $M$ is the mass of the molecule and $k T$ is Boltzmann's constant times the absolute temperature. 
For the case of high atmospheric pressure and $\beta \ll \lambda$, the mechanism of "evaporationcondensation" becomes "evaporation-diffusion through the atmosphere-condensation" which contributes $A^{\prime} \omega^{3}$ where:

$$
A^{\prime}=\rho_{0} D_{\mathrm{G}} \gamma_{\mathrm{s}} \Omega^{2} / k T
$$

in which $\rho_{0}$ is the equilibrium vapor density over a flat surface, and $D_{\mathrm{G}}$ is the diffusion coefficient of vapor molecules in the atmosphere.

The self-diffusion in the bulk crystal also depends on an $\omega^{3}$ term as $C \omega^{3}$ where

$$
C=D_{\mathrm{v}} \gamma_{\mathrm{s}} \Omega / k T
$$

in which $D_{\mathrm{v}}$ is the volume self-diffusion coefficient.

The surface diffusion term is expressed as $B \omega^{4}$ where

$$
B=D_{\mathrm{s}} \gamma_{\mathrm{s}} \Omega^{2} v / k T \text {. }
$$

Here, $v$ is the number of molecules per unit area, and $D_{\mathrm{s}}$ the surface self-diffusion coefficient.

Viscous flow contributes as $F \omega$, where

$$
F=\gamma_{\mathrm{s}} / 2 \eta
$$

Here, $\eta$ is the coefficient of viscosity.

A study of the power of $\omega$ dependence of

$$
K=B \omega^{4}+C \omega^{3}+A^{\prime} \omega^{3}+A \omega^{2}+F \omega
$$

would reveal the dominant mechanism of mass transfer at a fixed temperature. A series of measurements were made at $(-\mathrm{I} 0 \pm 0.5)^{\circ} \mathrm{C}$, in which the groove frequency was varied and the decay constant $K$ was calculated.

\section{EXPERIMENT}

The relaxation of grooves was observed by a Zeiss interference microscope enclosed in a constant-temperature box. The original thallium lamp was removed, and instead, a heliumneon CW gas laser $(6328 \AA, 0.3 \mathrm{~mW})$ was used as a light source outside the constant temperature box. This replacement was necessary for the following reasons: (I) To avoid temperature fluctuations in the constant-temperature box due to the heat generated by the thallium lamp.

(2) To increase the light intensity and decrease the exposure time. The exposure time was reduced from $\mathrm{I} 5 \mathrm{~min}$ to $30 \mathrm{~s}$ without a condenser lens and to $2 \mathrm{~s}$ with a condenser lens. (3) To increase the coherence of the illumination so that interference fringes will appear irrespective of the reference mirror adjustment. A mechanically actuated oscillating ground glass was used as a diffuser to eliminate the granular image which commonly appears in photography using a laser light source. The gap between the inset sample stage of the interference microscope and the objective lens was sealed by a thin flexible rubber film to enable the required adjustments to be made while the surface of the ice sample was kept in an icesaturated atmosphere. Because the alignment of the laser was critical, it was mounted on an adjustable platform. All other components were attached to a plywood base with heat glue to insure stability.

Mass transfer measurements were made on the (ooor) plane of naturally grown Mendenhall Glacier ice single crystals in the $\langle\mathbf{I O} \overline{\mathrm{I} O}\rangle$ direction. The impurity concentration of a good quality glacier ice single crystal is very small (Itagaki, $\mathrm{I}_{967}[\mathrm{~b}]$ ) and the dislocation density is very low ( $\mathrm{IO}^{4}$ to $\mathrm{IO}^{5} / \mathrm{cm}^{2}$ ) (Muguruma and Higashi, 1963 ; Fukuda and Higashi, I969). A large single crystal was cut down to a rectangular slab $(5 \mathrm{~cm} \times 3 \mathrm{~cm} \times \mathrm{I} \mathrm{cm})$ in the desired orientation and freeze-mounted on a glass slide $(5 \mathrm{~cm} \times 7.5 \mathrm{~cm})$. The top surface was smoothed without strain by the "freeze-tap method" (Tobin and Itagaki, I970). A series of periodic grooves (parallel to $\langle\mathrm{I} I \overline{2} \mathrm{O}\rangle$, spacing I9 to $80 \mu \mathrm{m}$ ) were engraved on the ice surface by a "hotwire grooving engine" (Tobin and Itagaki, I97I). The strain-free condition was satisfied during this procedure as verified by a low thermal etch-pit density. The strain-free condition 


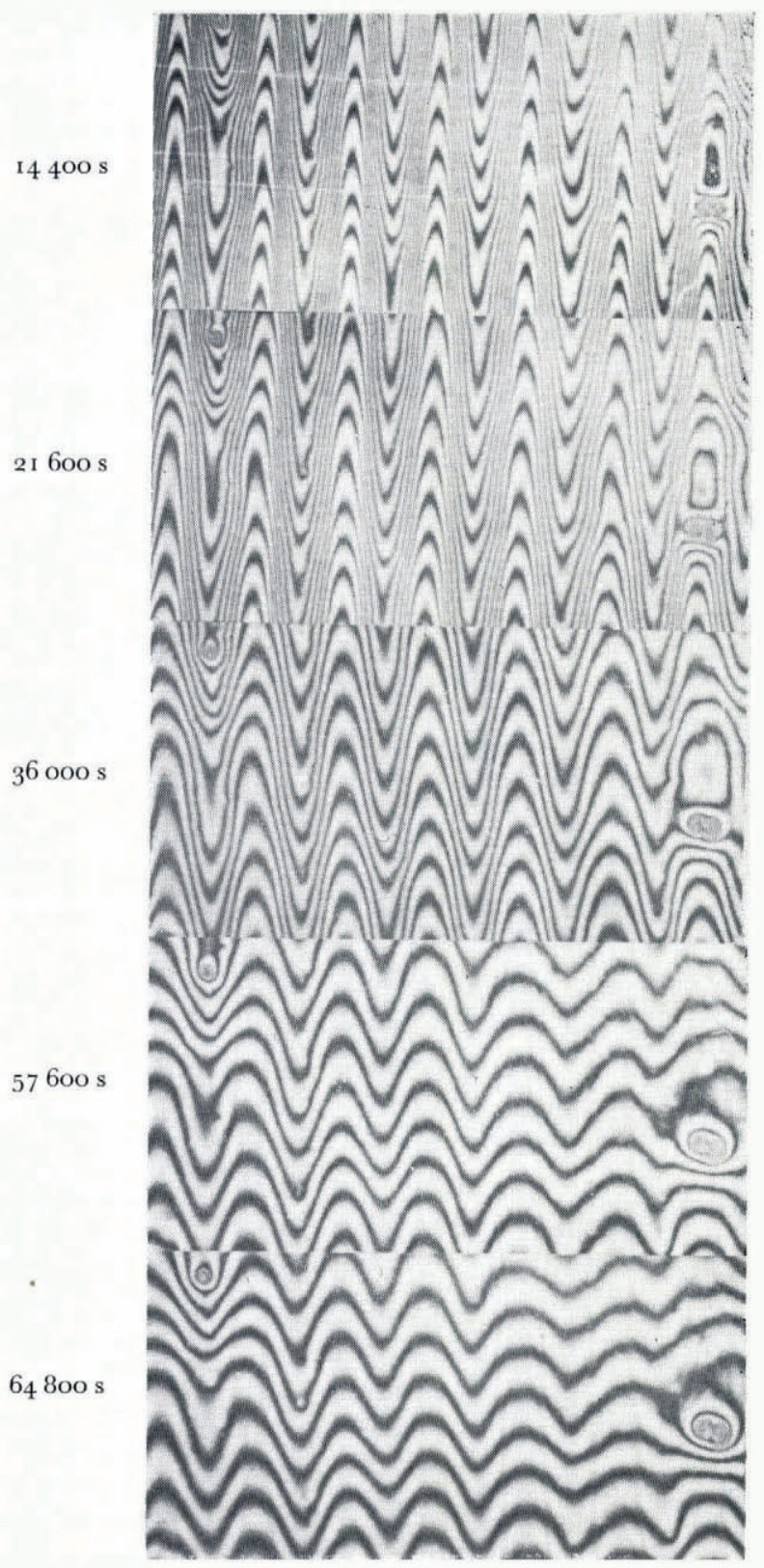

Fig. I. Series of interferograms indicating the decay of grooves. Wavelength $76.2 \mu \mathrm{m}$. Temperature $-10 \pm 0.5^{\circ} \mathrm{C}$. Fringe separation $=0.3^{1} 6 \mu \mathrm{m}$. Groove direction $\langle$ OOOI $\rangle$ on $(\mathrm{IO} \overline{\mathrm{I}} \mathrm{o})$ plane. 
must be fulfilled, otherwise a mass transfer mechanism activated by straining may overlap the other mechanisms and alter the results. The higher harmonics of the grooves rapidly decayed and smooth sinusoidal profiles appeared within a few hours.

The modification of surface profiles was recorded by interference photomicrographs as a function of time. The time period of observation for flattening ranged from $2 \mathrm{~h}$ for a $19 \mu \mathrm{m}$ groove spacing to $24 \mathrm{~h}$ for $80 \mu \mathrm{m}$ groove spacings. The depth of the grooves was measured by interpolating the interference fringes.

\section{RESULts}

Figure $\mathrm{I}$ is typical of the interference photomicrographs depicting the decay of grooves over an $18 \mathrm{~h}$ period. A few thermal etch pits appear in the field but do not interfere with amplitude measurements made in the center of the observation field.

The slope of the line obtained by the least-square fit of the plot of logarithm of depth versus time, as shown in Figure 2, is the decay constant, $K$.

The plot of $\log K$ versus $\log \lambda$ is linear as shown in Figure 3 . The slope of the least-square fit was $-\mathrm{I} .28$.

If any single mechanism dominates the process of groove decay, Equation (7) can be approximated as

$$
\kappa=k \omega^{n}=k(2 \pi / \lambda)^{n}=(2 \pi)^{n} k \lambda^{-n}
$$

where $n$ should be $1,2,3$ or 4 and $k$ correspondingly $F, A, A^{\prime}$ or $C$, or $B$. Consequently, a plot of $\log K$ versus $\log \lambda$ would have a slope of $-1,-2,-3$ or -4 . Since this plot of experimental data (Fig. 3) has a non-integral slope, the decay proceeds by at least a combination of two mechanisms or a new mechanism not considered in Mullins' theory.

\section{Discussion}

For the wavelengths used, the contributions from bulk diffusion and surface diffusion were calculated from Equations (4) and (5). These contributions are listed in columns 3 and 5 of Table I. As shown in columns 4 and 6 of Table I, the percentage contribution to the $K$ value obtained in this experiment from these terms is very small. The surface self-diffusion

Table I. Contribution of individual mechanisms to the decay constant $K$ as a function of Wavelength

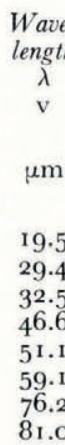

Wave-
length
$\lambda$
$\mathrm{v}$
$\mu \mathrm{m}$


19.5
29.4
32.5
46.6
51.1
59.1
76.2
81.0

I
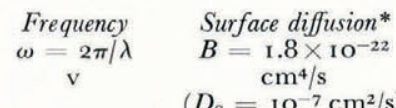

$\mathrm{mm}^{-1}$

322.2

213.7

193.3

I 34.5

I 23.0

106. 3

082.5

077.6

2

I 9.4038

3.7549

2.5137

$0.5^{892}$

0.4121

0.2299

0.0834

0.0653

3

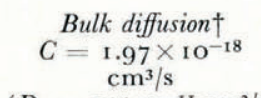

$$
\begin{gathered}
B \omega^{4} \\
\mathrm{Gs}^{-1}
\end{gathered}
$$

o.oog6

0.0034

0.0026

0.0009

0.0007

0.0005

0.0002

0.0002
$\left(D_{\mathrm{v}}=2 \times 1 \mathrm{O}^{-1 \mathrm{II}} \mathrm{cm}^{2} / \mathrm{s}\right)$

$\begin{array}{cl}C \omega^{3} & \% \text { of } K \\ \mathrm{Gs}^{-1} & \\ 65.726 & 0.033 \\ 19.177 & 0.017 \\ 14.192 & 0.015 \\ 4.781 & 0.0077 \\ 3.657 & 0.0065 \\ 2.360 & 0.0049 \\ 1.103 & 0.0030 \\ 0.918 & 0.0027\end{array}$

Column \#
$5 \quad 6$

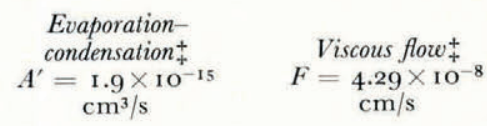

$A^{\prime} \omega^{3} \quad \%$ of $K^{\prime}$

$$
\mathrm{Ms}^{-1}
$$

63.55 $\quad 31.5$

I 8.54

1 3.723

4.62

3.536

2.282

0.887

${ }_{1} 38.22$

91.68

82.93

$57.7 \mathrm{O}$

52.77

45.60

$35 \cdot 39$

33.29

68.5

83.2

85.8

92.6

93.7

95.2

97.1

$97 \cdot 3$
I. 067

I 6.8

I 4.2

$7 \cdot 4$

6.3
4.8

2.9

2.7

7

8
F $\omega \quad \%$ of $K$

9

IO

${ }^{*} B$ was calculated from Equation (5) using $D_{\mathrm{s}}$ (Itagaki, unpublished) at $-10^{\circ} \mathrm{C}$.

$\dagger C$ was calculated from Equation (4) using approximate value of $D_{\mathrm{v}}$ (Itagaki, 1966) at $-10^{\circ} \mathrm{C}$.

$\ddagger A^{\prime}$ and $F$ are least-square fits of the present results. 


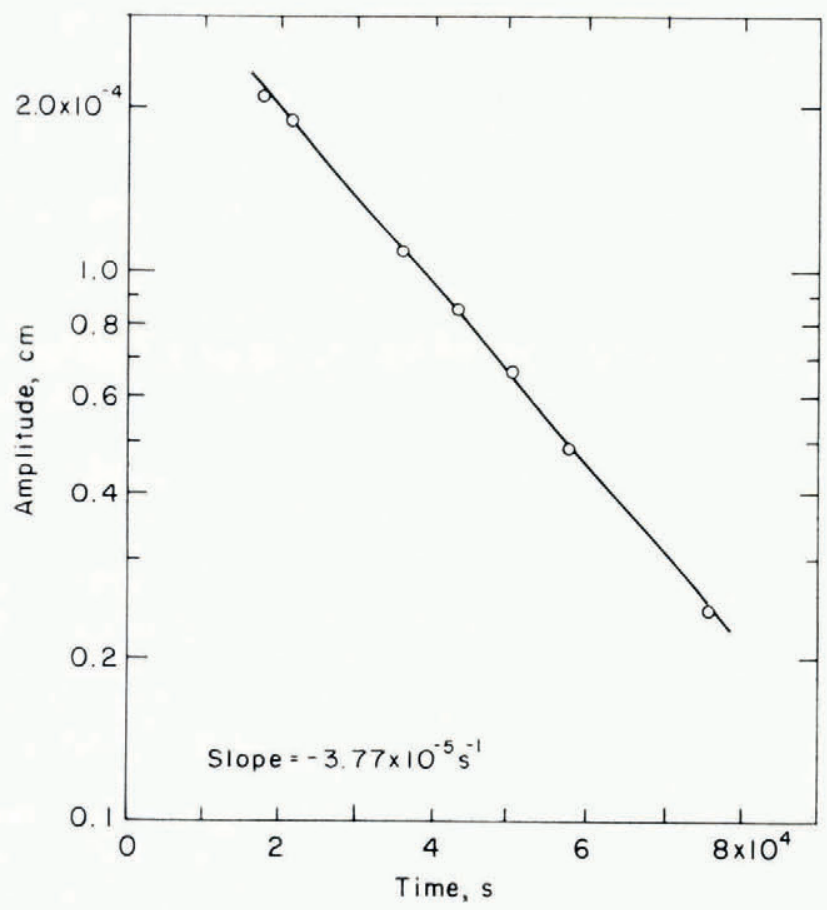

Fig. 2. Groove depth versus time. Wavelength $76.2 \mu \mathrm{m}$. Temperature $-10 \pm 0.5^{\circ} \mathrm{C}$. Slope equals the decay constant for this wavelength.

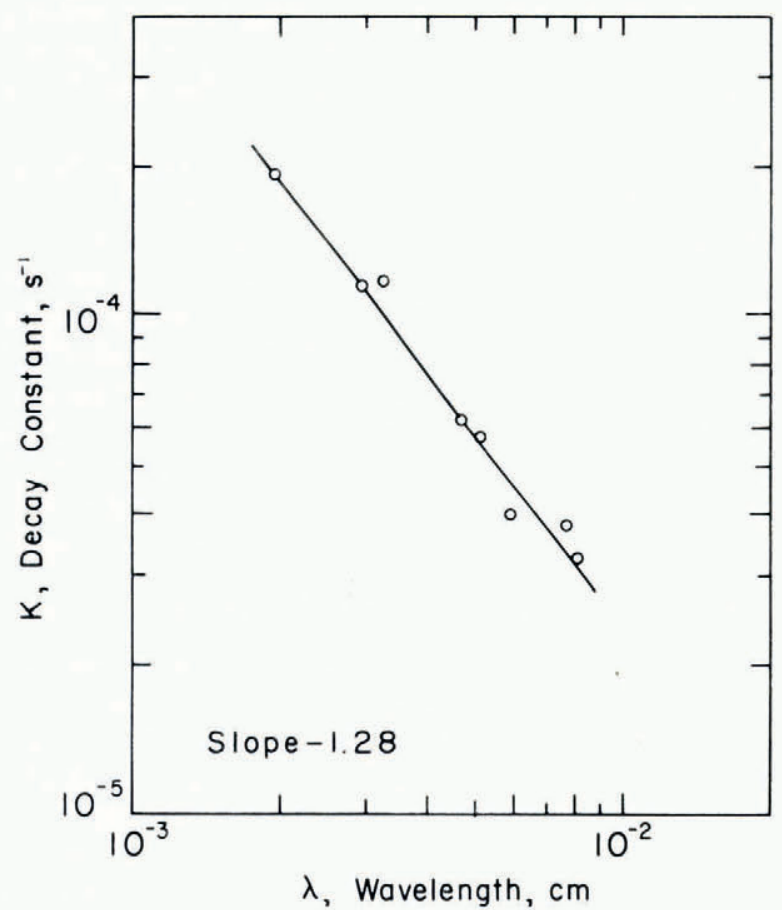

Fig. 3. Wavelength $\lambda$ versus decay constant $K$ at $-I O \pm 0.5^{\circ} \mathrm{C}$. 
coefficient in Equation (5) was obtained by a radioactive tracer method using microtomed ice surface (Itagaki, unpublished). This number may be larger than that for ice surfaces in this experiment because microtoming introduces strains into the ice surface. Even if the previously determined value is an order of magnitude in error, the percentage contribution to surface modification in the present study will still be negligible.

The direct evaporation-condensation mechanism cannot be responsible for groove decay since the mean free path of the water molecules under atmospheric pressure is three orders of magnitude smaller than the wavelength range used. The term containing $A$ is therefore omitted.

Only two mechanisms, "evaporation-diffusion through the atmosphere-condensation" and "viscous flow", remain responsible for the groove decay and will contribute as an $\omega^{3}$ and $\omega$ dependence respectively.

The values $A^{\prime}$ and $F$ were fitted to the measured decay constants for each value of $\omega$ as the coefficient of $\omega^{3}$ and $\omega$ terms by a least-squares method.

The results are $A^{\prime}=\mathrm{I} .9 \times 10^{-21} \mathrm{~m}^{3} \mathrm{~s}^{-1}$ and $F=4.29 \times 10^{-10} \mathrm{~m} \mathrm{~s}^{-1}$. As can be seen in the columns 8 and io of Table I the major mechanisms of groove decay are predominantly "viscous-flow type" with a smaller contribution from the "evaporation-diffusion through the atmosphere-condensation" mechanisms which contributed a maximum of $c .30 \%$ for the shortest wavelength measured. This result is based on the assumptions that (I) only two mechanisms are operative and (2) the contributions of the mechanisms to groove decay are proportional to $\omega^{3}$ and $\omega$ respectively and are additive.

Both $F$ and $A^{\prime}$ can be theoretically calculated, from Equations (6) and (3) respectively. However, the $F$ values calculated from Equation (6) using known values of viscosity are $2 \mathrm{I} \mathrm{m} \mathrm{s}{ }^{-1}$ for supercooled water and $6.8 \times \mathrm{IO}^{-15} \mathrm{~m} \mathrm{~s}^{-1}$ for river ice. Neither of these is correct. The former is unrealistic because the viscosity assumed is that of a supercooled water and not ice. The latter viscosity is obtained from the macroscopic deformation of river ice and may not be applicable to the present case since the actual viscous deformation of bulk single crystal must be through dislocation motion. The lack of etch pits in the area measured, however, does not support dislocation motion as the mechanism for the surface flattening seen here.

Any of the anomalous surface features postulated by many researchers (for example, Faraday, I86o; Weyl, I951; Nakaya and Matsumoto, r953; Fletcher, I962, I968; Jellinek, I967) including a liquid layer, two-dimensional liquid layer, a high point-defect density layer (Itagaki, I967[a],[c]) etc., could account for the groove decay observed in this experiment.

If the viscous flow is not in the bulk crystal viscosity as considered in Mullins' theory but limited to the surface layer, the Mullins equation for the viscous-flow contribution may have to be modified to a certain extent. A study on this problem is in progress.

The theoretical value of $A^{\prime}=\rho_{0} D_{\mathrm{G}} \gamma_{\mathrm{s}} \Omega^{2} / k T$ is $4.37 \times \mathrm{IO}^{-20}$ molecules $\mathrm{m}^{3} / \mathrm{s}$ at $-\mathrm{IO}^{\circ} \mathrm{C}$. This value is more than twenty times larger than the measured value. Hobbs and Mason (1964) suggested that a correction must be made for materials with high latent heat of sublimation and low thermal conductivity such as ice. This correction replaces the $\rho_{0} \Omega D_{\mathrm{G}}$ term in $A^{\prime}$ with $\left[\frac{k T_{\rho}}{\rho_{0} m D_{\mathrm{G}}}+\frac{L_{\mathrm{s}}^{2} m}{K_{\mathrm{t}} k T^{2}}\right]^{-\mathrm{I}}$ where $\rho$ is the density of ice, $m$ is the molecular mass of water, and $K_{\mathrm{t}}$ is the thermal conductivity of air. The correction reduces the calculated $A^{\prime}$ to $3.35 \times \mathrm{IO}^{-20}$, but it is still $\mathrm{I}_{7}$ times larger than the measured value.

There are some possible sources of this discrepancy both in the theoretical calculation and experimental results. The surface free energy has been measured by an indirect method giving values ranging from 0.085 to $0.122 \mathrm{~J} \mathrm{~m}^{-2}$. The most direct measurement made by Ketcham and Hobbs ( 1969 ) resulted in the value of o. $109 \mathrm{~J} \mathrm{~m}^{-2}$ which was used for the present calculation. Though the variation of the value could not be the sole source of the discrepancy it would contribute to a certain degree. 
Another possible source of error is the vapor density $\rho_{0}$ used to calculate the evaporationcondensation term. This term is based on the assumption that the process can be described by macroscopic thermodynamics. This notion, however, may not be correct. Evaporationcondensation on a crystal surface must be treated as growth and sublimation of a crystal, which would follow spiral growth, (Frank, 1949; Burton and others, I95I), and evaporation (Cabrera and Levine, I956), due to dislocations. The recent measurement by Lester and Somorjai ( 1968 ) indicated that the evaporation rate of a $\mathrm{NaCl}$ crystal with a dislocation density $\mathrm{IO}^{10} / \mathrm{m}^{2}$ is 2.5 times slower than that of a crystal with a dislocation density of $\mathrm{IO}^{\mathrm{II}} / \mathrm{m}^{2}$.

The present crystal has a much lower dislocation density $\left(\mathrm{IO}^{8}-\mathrm{IO}^{9} / \mathrm{m}^{2}\right)$. In addition the measurements were made in a selected area with no dislocation etch pits as shown in Figure $\mathrm{I}$. The evaporation-condensation process under such low dislocation density would be much slower than predicted by a theory based on simple thermcdynamic considerations. However, the extent of this effect on the present study is not known. Some other effect such as the impurity cover on the ice or undersaturation of water vapor in the atmosphere may also reduce the rate of evaporation-condensation though the contribution is not known yet.

The present result indicates that mass transfer on an ice surface may take place by mechanisms not accounted for in the Mullins' theory. Possible models for this behavior could include enhanced surface layer diffusion and viscous flow of a two-dimensional liquid.

MS. rceived 2 March 1972

\section{REFERENCES}

Burton, W. K., and olhers. 1951. The growth of crystals and the equilibrium structure of their surfaces, by W. K. Burton, N. Cabrera and F. C. Frank. Philosophical Transactions of the Royal Society, Vol. 243, No. 866, p. 299-358, Cabrera, N., and Levine, M. M. 1956 . On the dislocation theory of evaporation of crystals. Philosophical Magazine.
Eighth Ser., Vol. 1, No. 5, p. $450-58$.

Faraday, M. 1860. Note on regelation. Proceedings of the Royal Society, Vol. 10, p. 440-50.

Frank, F. C. 1949. The influence of dislocations on crystal growth. Discussions of the Faraday Society, No. 5, p. $4^{8-54}$.

Fukuda, A., and Higashi, A. 1969. X-ray diffraction topographic studies of dislocations in natural large ice single crystals. Fapanese Fournal of Applied Physics, Vol. 8, No. 8, p. 993-99. Hobbs, P. V., and Mason, B. J. 1964. The sintering and adhesion of ice. Plilosophical Magazine, Eighth Ser.,
Vol. 9, No. 98, p. 181-97. Itagaki, K. 1966 . Self-diffusion in ice single crystals. U.S. Cold Regions Research and Engineering Laboratory.
Reserch Report 178 .

Itagaki, K. I967[a]. Particle migration cn ice surf ces. (In Ōura, H., ed. Fhysics of snow and ice: international conference on low temperature science. ... Ig66. ... Proceedings, Vol. I, Yt. I. [Sapporo], Institute of Low Temperature Science, Hokkaido University, p. 233-46.)

Itagaki, K. 1967[b]. Self-diffusion in single-crystal ice. Journal of the Physical Society of Japan, Vol. 22, No. 2, p. $427-3 \mathrm{I}$.

Itagaki, K. ${ }^{1967[c]}$. Some surface plenomzna of ice. Journal of Colloid and Interface Science, Vol. 25, No. 2, p. $218-27$. Jellinek, H. H. G. 1967 . Liquid-like (transition) layer on ice. Journal of Colloid and Interface Science, Vol. 25, No. 2,
p. 192-205.

Ketcham, W. M., and Hobbs, P. V. 1959. An experinental determination of the surface energies of ice. Philosoplical Magazine, Eighth Ser., Vol. 19, No. I62, p. i 16 6 -73. Lester, J. E., and Somorjai, G. A. 1968. The effect of dislocations on the vaporization rate of NaCl single crystals.
App'ied Physics Lellers, Vol. 12, No. 6, p. 216-17.

Muguruma, J., and Higashi, A. 1963 . Observation of etci channels on the (Ooor) plane of ice crystal produced by nonbasal glide. Fournal of the Physical Society of Japan, Vol. 18, No. 9, p. $1261-69$. Mullins, W. W. I959. Flattening of a nearly plane solid surface due to capillarity. Fournal of Applied Physics,
Vol. 30, No. 1, p. 77-83.

Nakaya, U., and Matsumoto, A. 1953. Evidence of the existence of a liquid like film on ice surfaces. U.S. Snow, Ice and Permafrost Research Establishment. Research Paper 4.

Tobin, T. M., ant Itagaki, K. I970. Instruments and methods. A technique for producing strain-free flat surfaces on single crystals of ice. Fournal of Glaciology, Vol. 9, No. 57, p. $385-90$.

Tobin, T. M., and Itagaki, K. I971. A hot-wire grooving engine to produce periodic grooves on an ice surface. Journal of Glaciol gy, Vol. 10, No. 58, p. $139-4^{2}$. Weyl, W. A. r 95 I. Surface structure of water and some of its physical and chemical manifestations. Fournal of
Colloid Science, Vol. 6 , No. 5, p. 389-405. 